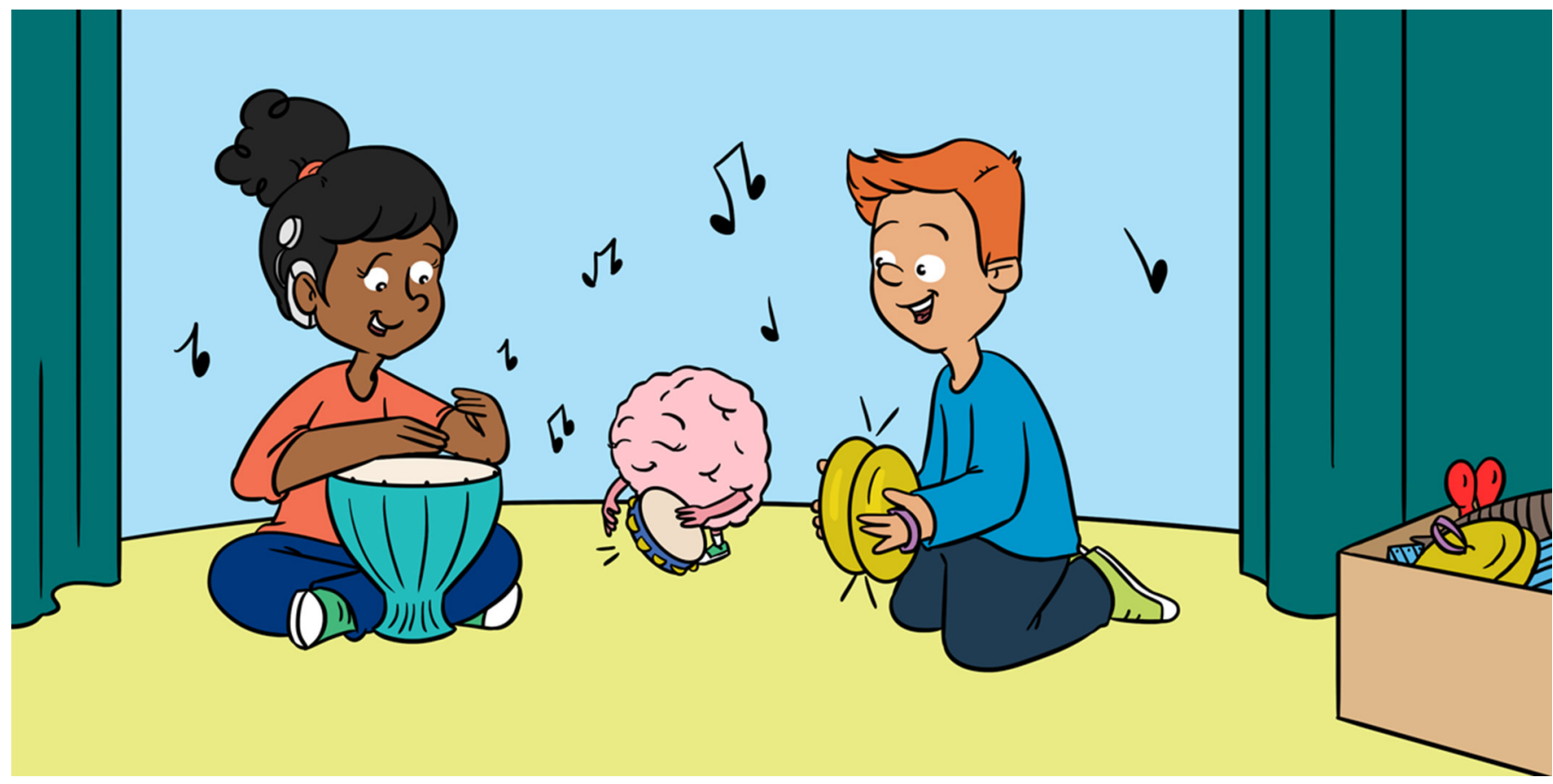

\title{
CAN MUSIC TRAINING IMPROVE LISTENING SKILLS FOR CHILDREN WITH HEARING LOSS?
}

Chi Yhun Lo ${ }^{1,2,3^{*}}$, Valerie Looi ${ }^{4}$, William Forde Thompson ${ }^{1,3}$ and Catherine M. McMahon ${ }^{1,2,3}$

${ }^{1}$ Department of Linguistics, Macquarie University, Sydney, NSW, Australia

${ }^{2}$ The HEARing CRC, Melbourne, VIC, Australia

${ }^{3} A R C$ Centre of Excellence in Cognition and its Disorders, Sydney, NSW, Australia

${ }^{4}$ SCIC Cochlear Implant Program-An RIDBC Service, Sydney, NSW, Australia

YOUNG REVIEWERS:

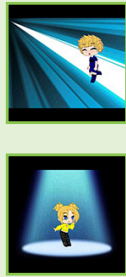

AARON

AGE: 11

ISLA

AGE: 9
Hearing aids and cochlear [ko-clear] implants are very useful devices for children with hearing loss. But they do not completely restore hearing. Many children with hearing loss find it difficult to listen in noisy places like the playground. This is important because many social interactions create noise or occur in noisy places. While most people think we listen through our ears, it is the brain that does most of the hard work! We thought that music training might be a good way to improve listening skills. Why? Because music is a fun activity that involves not only sounds, but also sights, movement, memory, and more! This means a lot of activity and learning, which is good for the brain. What did we find? After 12 weeks of music training, children with hearing loss were better at listening, particularly in noisy environments. 
Figure 1

The hearing pathway. Sound is collected by the outer ear; the middle ear amplifies sound (making sound louder); and the inner ear transforms sound into electrical signals, which travel to the brain. Finally, the brain gives meaning to these electrical signals.

\section{HEARING PATHWAY}

How sound travels from the ear to the brain and is given meaning.

\section{HEARING LOSS}

A problem at some point in the hearing pathway that usually means hearing difficulties.

\section{HEARING AID}

An assistive listening device that amplifies sounds.

\section{COCHLEAR \\ IMPLANT}

An assistive listening device that bypasses the outer and middle ear, and sends electrical signals to the inner ear. Sometimes known as the bionic ear.

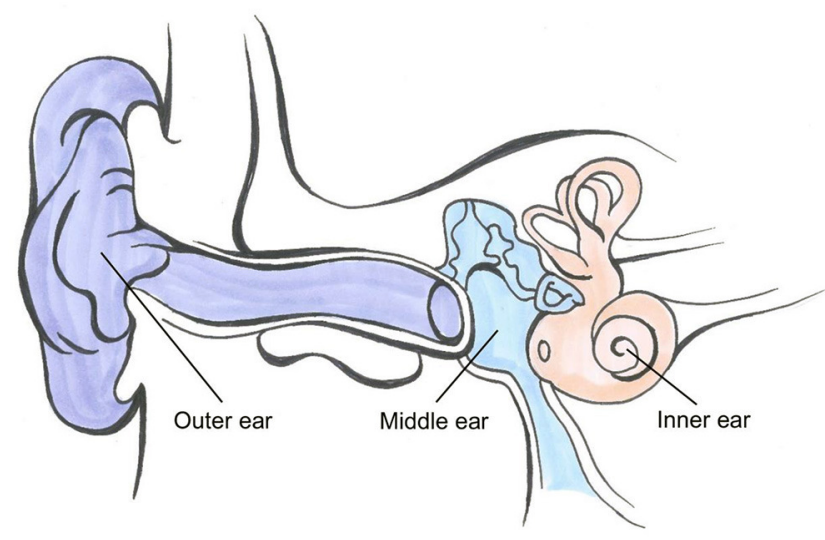

Figure 1

\section{GOOD VIBRATIONS}

Did you know that sound is made by objects vibrating? When you hear a person speaking, you are hearing the vibrations of their voice traveling through the air as sound waves. Try resting your hand gently on your throat and say, "bees buzz loudly." Did you feel your throat vibrate? These vibrations are made in your voice box, or larynx [la-rinks].

Sound made by people or objects pass through the air and into your ears. Ears are made up of three sections. The outer ear collects and funnels sound; the middle ear amplifies sound, which means it makes sound louder; and the inner ear transforms sound into electrical signals, which travel to the brain. Finally, the brain gives meaning to these electrical signals. This is how we understand or perceive sound. This whole process is called the hearing pathway (Figure 1). You might be surprised to learn that your brain, not your ears, is the most important part of hearing! Your brain lets you hear all sorts of sounds like waves crashing at the beach, laughter, and songs. What are your favorite sounds, and what do they mean to you? Is music your favorite sound? Did you know that learning music can help people with hearing loss?

\section{DID YOU HEAR THAT?}

Hearing loss occurs when there is a problem at some point in the hearing pathway. A child with a mild hearing loss might have difficulties with soft sounds like whispering. Someone with a profound hearing loss might only be able to hear very loud sounds, like a jet engine or an emergency siren.

Hearing aids and cochlear implants are commonly used to improve hearing loss (Figure 2). Hearing aids pick up sound with a small microphone. These sounds are amplified and come out of a 
Figure 2

The child on the left uses a red hearing aid. Hearing aids work by making sounds louder. The child on the right has a blue cochlear implant. Cochlear implants work by sending electrical signals directly to the inner ear.

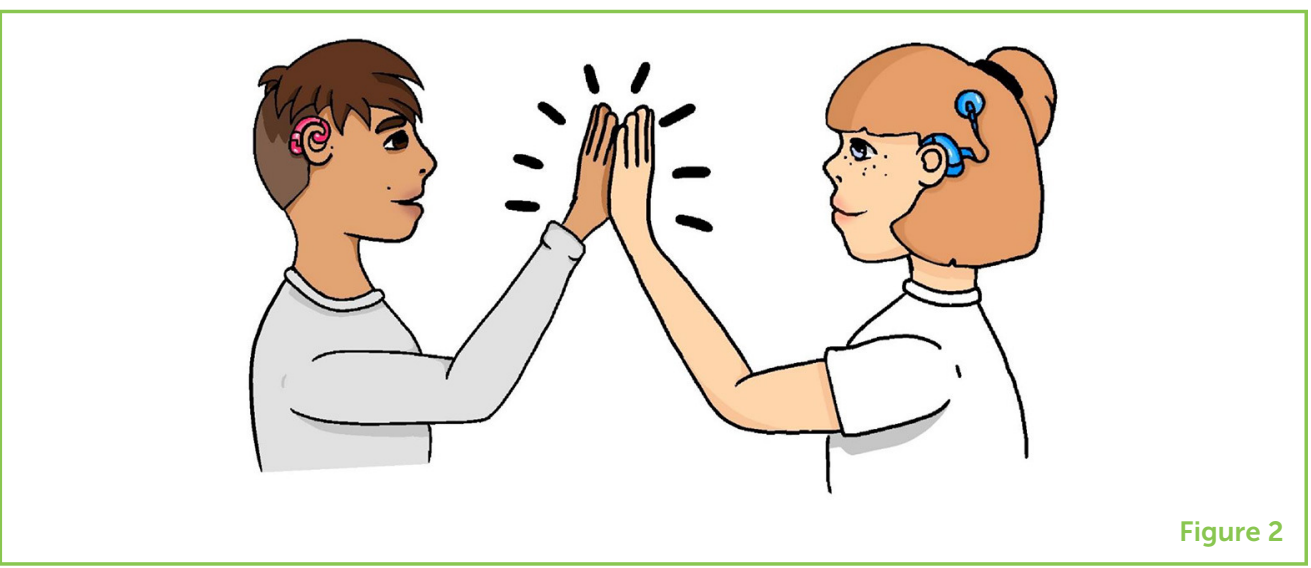

miniature loudspeaker into the ear. Hearing aids work like headphones and mostly make sounds louder. But cochlear implants work very differently. They pick up sounds and send electrical signals directly to the inner ear. Some adults describe the cochlear implant as sounding tinny, robotic, and electric [1]. Fortunately, the brain has an extraordinary capacity to adapt! So, people find that these devices sound better with time, effort, and experience.

Hearing aids and cochlear implants are very useful devices. But they are not like glasses that make everything clear and readable when you put them on. Many children who use hearing aids or cochlear implants find it difficult to listen in noisy places. This can be a huge problem, especially because we often need to talk in noisy environments. Think about how noisy it gets during a class discussion, chatting with your friends in the playground, at a birthday party, or at a busy restaurant. Imagine how much you would miss if you could not hear well in those situations.

\section{MUSIC TO YOUR EARS, BUT MOSTLY FOR THE BRAIN!}

Musical activities use lots of brain power! Imagine you are playing the piano. As you read the sheet music in front of you, your eyes tell your fingers which keys to play. Each key you play creates sound, and your ears and brain provide feedback about whether you have played the correct notes. You might be able to play a song by memory, and you can even make up your own song. You can invite other musicians to form a band and play together. All these aspects of music provide the brain with a complete workout-one that relies on sound, vision, memory, creativity, social skills, and more!

The most common way to explore the benefits of music is to look at the differences between professional musicians and someone with little or no musical training. An important discovery is that professional musicians are better at listening in noisy environments than non-musicians are [2]. This means that they are good at hearing 
what people are saying at a party and they can ignore all the background noise. How do musicians gain this skill? Some may have been born with good listening skills, which could have made them more likely to enjoy music in the first place [3]. But others may have learned to listen better through years of practice. One study showed that children improved their listening skills after 2 years of music training [4]! So, like most things, your ability to listen in noisy environments probably has something to do with natural talents and lots of practice [5]. You can learn more about music in the brain in this Frontiers for Young Minds article, and this one [6, 7].

\section{EXPERIMENT TIME, WHAT DID WE LEARN?}

Scientists are only just beginning to understand how music might help children with hearing loss. To explore this, we studied 14 children (between 6 and 9 years of age) with hearing loss, both before and after they received music training. To keep things fair, we only selected children who were born with a moderate to profound hearing loss and who were using hearing aids and/or cochlear implants.

How did we measure listening skills? We asked each child to listen to twenty different sentences such as: "They broke all the eggs"; "Children like strawberries"; or "The clown had a funny face". The tricky part was that four other voices were also talking in the background, which made things pretty noisy! Every time a child repeated most of the sentence correctly, the noise would become louder. This made the next sentence more difficult to hear. If the child got most of the sentence wrong, the noise would become softer, making the next sentence easier to hear. After doing this 20 times, we calculated each

SPEECH-IN-NOISE SCORE

A score of how well a person can listen in noise.

\section{TIMBRE}

How we describe the different sounds of instruments or voices, even if they are playing the same song, pitch, or melody. child's speech-in-noise score. A good speech-in-noise score means that a person can understand speech even when surrounded by lots of loud noise.

To measure our children's musical skills, we used a test of timbre [tam-ber]. Timbre is how we describe instruments or voices sounding different, even if they are playing the same song at the same speed and volume. Some people like to think of timbre as describing the texture of sound. For example, if you played "Happy Birthday" on a xylophone, it would have a different timbre than if you played it on a harp, or if you sang it. It is timbre that lets you know which instrument is which. In this test, the children had to identify which instrument was playing a short tune. There were eight possible instruments to choose from: piano, violin, cello, acoustic guitar, trumpet, flute, clarinet, and saxophone.

Before the children started music training, we measured their listening and musical skills. twice-12 weeks apart. This baseline measurement result showed that, after simply living their lives as usual, there was 
Figure 3

The music training that the children in our experiment received included (A) playing and listening to percussion with blindfolds on, and (B) playing together as a band.
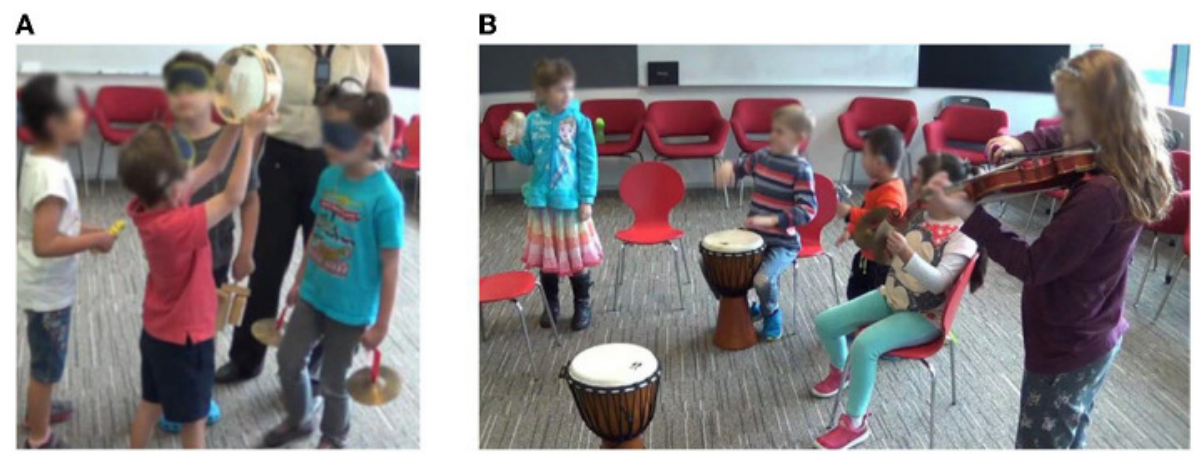

Figure 3

no change to any of their skills. The children did no training, and their listening skills did not improve.

After this baseline test, the children began a 12-week course of music training. They joined other children for music therapy such as drumming, singing, and dancing together (Figure 3). They also played musical apps on smart phones or tablets in their own time. These included "drawing" songs, or matching sounds to instruments. At the end of the 12 weeks of music training, we measured the children's musical and listening skills again. And this time, we found some improvements!

We discovered that children who had completed the training were better at listening to speech in a noisy environment, which was what we were hoping for! The children were also better at identifying various instruments and perceiving timbre. Timbre gives us an important clue about why the children improved in their abilities to listen in noisy environments.

Imagine you are in class, trying to listen to your teacher on a noisy day. There might be all sorts of unwanted, distracting sounds around you. Other children are speaking, footsteps echo through the hallway, students type on keyboards, and laughter from the playground leaks through the window. All these sounds can add up together to become noise. To focus on your teacher's voice, your brain needs to identify which sounds you want to listen to and which sounds are noise that you want to ignore. Timbre perception helps you do this. You can learn more about separating sounds in this Frontiers for Young Minds article [8].

Parents of the children also noticed improvements. One said: "We would like to continue with the music program, as our son has made significant progress in the 12 weeks, and we would love for him to go further again! We have noticed that he has become quicker to identify songs on the radio. Even more astounding is that he has suddenly 
developed some intonation and tune to his singing along, which was previously non-existent."

\section{ALL TOGETHER NOW!}

Hearing aids and cochlear implants are amazing devices that help restore some hearing, but not all of it. A common difficulty for children with hearing loss is listening and interacting in noisy environments. It is important to explore ways to improve this skill, as the world can be a very noisy place! We thought music would be a good activity to investigate, as music generates a lot of brain activity. As you now know, the brain is where the most critical part of hearing occurs. After 12 weeks of music training, the children with hearing loss were better at listening in a noisy environment. We hope this will help children with hearing loss live happier lives in noisy and important places like the classroom and playground!

\section{ACKNOWLEDGMENTS}

This study was supported by the Macquarie University Research Enhancement Fund and the financial support of The HEARing CRC. We are grateful to the efforts of the children and their families. We thank Eudora Low and Nordoff-Robbins Music Therapy Australia for facilitating the music therapy sessions. Finally, a big thank you to Grace Howlader for drawing the figures and bringing life to this article.

\section{ORIGINAL SOURCE ARTICLE}

Lo, C. Y., Looi, V., Thompson, W. F., and McMahon, C. M. 2020. Music training for children with sensorineural hearing loss improves speech-in-noise perception. J. Speech Lang. Hear. Res. 63:1990-2015. doi: 10.1044/2020_JSLHR-19-00391

\section{REFERENCES}

1. Peters, J. P. M., Wendrich, A. W., Van Eijl, R. H. M., Rhebergen, K. S., Versnel, H., and Grolman, W. 2018. The sound of a cochlear implant investigated in patients with single-sided deafness and a cochlear implant. Otol. Neurotol. 39:707-14. doi: 10.1097/MAO.0000000000001821

2. Coffey, E. B. J., Mogilever, N. B., and Zatorre R. J. 2017. Speech-in-noise perception in musicians: a review. Hear. Res. 352:49-69. doi: 10.1016/j.heares.2017.02.006

3. Schellenberg, E. G. 2015. Music training and speech perception: a gene-environment interaction. Ann. N. Y. Acad. Sci. 1337:170-7. doi: 10.1111/nyas.12627

4. Slater, J., Skoe, E., Strait, D. L., O'Connell, S., Thompson, E., and Kraus, N. 2015. Music training improves speech-in-noise perception: longitudinal evidence 
from a community-based music program. Behav. Brain Res.

291:244-252. doi: 10.1016/j.bbr.2015.05.026

5. Hambrick, D. Z., Mcnamara, B. N., and Oswald, F. L. 2020. Is the deliberate practice view defensible? A review of evidence and discussion of issues. Front. Psychol. 11:1134. doi: 10.3389/fpsyg.2020.01134

6. Pienkowski, M. 2015. Music is good for your brain, but don't blast it. Front. Young Minds. 3:8. doi: 10.3389/frym.2015.00008

7. Musacchia, G., and Khalil, A. 2020. Music and learning: does music make you smarter? Front. Young Minds. 8:81. doi: 10.3389/frym.2020.00081

8. Aubuchon, A., and Mccreery, R. 2020. When choosing NOT to listen helps you hear and learn. Front. Young Minds. 8:104. doi: 10.3389/frym.2020.00104

SUBMITTED: 01 May 2021; ACCEPTED: 21 December 2021;

PUBLISHED ONLINE: 14 January 2022.

EDITOR: Naomi Curati, The University of Manchester, United Kingdom

SCIENCE MENTOR: Bryony Buck

CITATION: Lo CY, Looi V, Thompson WF and McMahon CM (2022) Can Music Training Improve Listening Skills For Children With Hearing Loss? Front. Young Minds 9:704006. doi: 10.3389/frym.2021.704006

CONFLICT OF INTEREST: CL is currently employed as a consultant for Cochlear Limited. VL was previously employed by Advanced Bionics. However, Cochlear Limited and Advanced Bionics have had no input into any part of this study or this article.

The remaining authors declare that the research was conducted in the absence of any commercial or financial relationships that could be construed as a potential conflict of interest.

COPYRIGHT (c) 2022 Lo, Looi, Thompson and McMahon. This is an open-access article distributed under the terms of the Creative Commons Attribution License (CC BY). The use, distribution or reproduction in other forums is permitted, provided the original author(s) and the copyright owner(s) are credited and that the original publication in this journal is cited, in accordance with accepted academic practice. No use, distribution or reproduction is permitted which does not comply with these terms.

\section{YOUNG REVIEWERS}

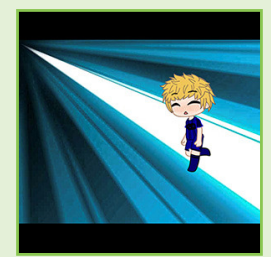

\section{AARON, AGE: 11}

Aaron is 11 years old and likes going on skiing holidays. He loves computer games and sports. His faourite subjects are maths (sometimes!) and P.E. His dream place to visit would be Italy because it has all the things he loves: really good food, beaches, and the alps for skiing. Aaron and Isla are brother and sister. They live in Scotland and love playing and annoying each other! They have great imaginations and are fantastic at coming up with new experiments. 


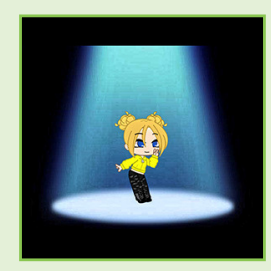

\section{ISLA, AGE: 9}

I love rainbow belts and food. I have an annoying brother, Aaron. I love Hamilton, trampolining, my teddies, and my best friends. My personality is drama. I would love to go to America because it has amazing sweets. I care for my friends and family. My favorite subject is art I want to be a painter in houses when I am older and have a room in my own house where I can paint on the walls and discover new designs.

\section{AUTHORS}
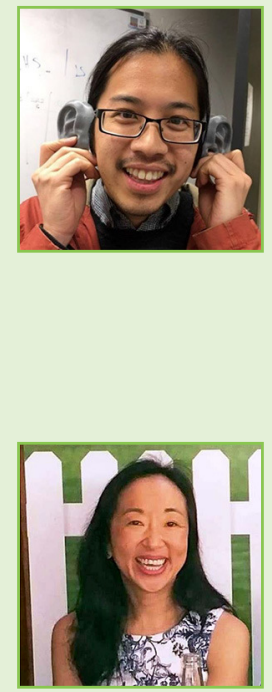

\section{CHI YHUN LO}

I am a research fellow at the Australian Institute of Health Innovation, an adjunct fellow at Macquarie University in Australia, and the committee secretary of the Parents of Deaf Children. Communication is central to what makes us human, and I find the act of listening wonderful and intriguing! I am interested in the role of music in the lives of people who are deaf and hard-of-hearing. Before studying to become a researcher, I was a musician and audio engineer, making and mixing sounds. So, it is probably no surprise that I will always find time for music! *chi.lo@mq.edu.au

\section{VALERIE LOOI}

I am an audiologist, music therapist, and researcher who specializes in researching how adults and children with cochlear implants ( $\mathrm{Cls}$ ) and hearing aids hear music, and how this could be improved. I used to work for two $\mathrm{Cl}$ companies where I managed their research across all of the Asia-Pacific region, but I am now the general manager for Advance Healthcare. However, I continue to help with research related to music for those with Cls or hearing aids, and particularly music training to help improve music listening, because it is a big passion of mine to help people with hearing loss enjoy music more, and to get better at it.

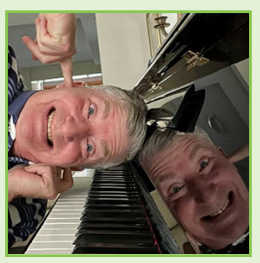

\section{WILLIAM FORDE THOMPSON}

I am director of the Music, Sound and Performance Laboratory and a distinguished professor at Macquarie University, Sydney, Australia. I became interested in music as a child growing up in Canada, where I spent hours every day making up new sounds and melodies on the piano, and driving my parents crazy. Music became a "friend" to me, and eventually I found other kids who had the same friend! I believe music can benefit all people, making us feel good and helping us understand ourselves and others. In my research, I want to find out why music is so powerful.

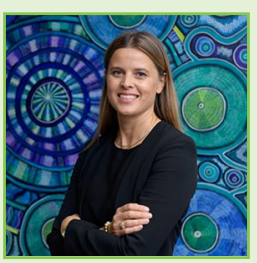

\section{CATHERINE M. MCMAHON}

I am a professor of audiology at Macquarie University in Australia. I work in the Australian Hearing Hub with many researchers and teachers, innovators who develop hearing technologies, and specialists who work with people who have hearing loss. I spend much of my time doing interesting research with individuals and communities in Australia and overseas to improve the ways that we all can take care of our hearing. I also teach university students to become great audiologists, so they can measure hearing levels and fit hearing aids and cochlear implants for babies, kids, and adults who have hearing loss. 